\title{
Entre a utopia e o ceticismo: as potencialidades dos diários virtuais no mercado de comunicação nacional ${ }^{1}$
}

\author{
Mariana Della Dea Tavernari (ECA-USP) ${ }^{2}$
}

\section{Resumo}

Os diários virtuais são elementos-chave para compreender como se articulam as profecias otimistas e pessimistas em conseqüência da emergência de novas mídias e formatos no mercado de comunicação nacional. Sob a ótica da remediação, apresentam-se como uma alternativa à unilateralidade imposta pelos meios tradicionais ao introduzirem uma narrativa expressiva similar ao jornalismo literário aportada no ambiente bilateral e interconectado da Internet e tornam-se os alvos principais dos entusiastas que idealizam a concretização do chamado jornalismo cidadão.

Palavras-chaves: Weblog; diário virtual; internet; jornalismo; comunicação

\begin{abstract}
Web diaries are key elements for us to understand how optimistic and pessimistic prophecies are articulated in consequence of the emergence of new media and models in the national communication market. Under the perspective of comfort, they present themselves as an alternative to the unilaterality imposed by the traditional media. It is introduced an expressive narrative similar to the literary journalism anchored in the bilateral and interconnected environment of the internet and so they become the main target of the enthusiasts, the ones that idealize the so called communitarian journalism.
\end{abstract}

Keywords: Weblog, virtual diary, internet, journalism, communication 
Entre as diversas profecias neo-luditas e tecno-utópicas a respeito das transformações promovidas pela emergência de novos meios de comunicação, o surgimento da Internet ocupa uma posição de destaque: enquanto entusiastas defendem a emergência de uma nova forma de expressão democrática, pessimistas temem pelo desaparecimento de veículos de comunicação audiovisuais e impressos. Teóricos ao longo do período de desenvolvimento dos meios digitais se aventuraram a profetizar as consequiências da emergência de um espaço virtual de troca de dados e informações em formato digital. No entanto, os avanços do meio on-line, bem como as tentativas de compreensão acadêmica das funcionalidades e potencialidades dos diários virtuais, também denominados weblogs ou blogs, comprovam a inadequação dos radicalismos tecnológicos.

Se, por um lado, o mercado dos jornais brasileiros encolhe anualmente, seguindo tendência mundial de queda, recém-lançadas revistas especializadas são vendidas em bancas de todo o país. Ignorar profecias extremistas parece ser a primeira empreitada para um aprofundamento dos conhecimentos a respeito de novas mídias, mas não se pode negar a importância das transformações promovidas por elas.

Altera-se não apenas o mobiliário das empresas, mas também o fluxo produtivo de informação, bem como suas ferramentas de veiculação e distribuição. Na década de 90, a Internet, marcada pela interconexão, interatividade e hipertexto, revoluciona o cenário do mercado de comunicação nacional e passam a ser veiculadas pelo ambiente virtual as publicações eletrônicas jornalísticas, principalmente as versões on-line dos jornais impressos.

Análises a respeito do caráter dinâmico da Internet, como a combinação, em um mesmo suporte, de sons, textos e imagens, a facilidade de manipulação do conteúdo e a possibilidade de interatividade, pressupõem conceitos que permitam analisar além dos extremismos e possibilitem a compreensão de seus fenômenos de maneira complexa. No contexto das novas tecnologias, nenhum meio de comunicação pode funcionar independente de outros meios de comunicação, nem pode ter seu próprio significado cultural. Todos parecem se interligar, se recombinarem, e até competirem entre si.

"Nem os dispositivos de comunicação, nem os modos de conhecimentos, nem os gêneros característicos da cibercultura irão pura e simplesmente substituir os modos e gêneros anteriores. Irão antes, por um lado, influenciá-los e, por outro lado, forçá-los a encontrar seu "nicho" específico dentro da nova ecologia cognitiva. O resultado global será (já é!) uma complexificação e uma reorganização da economia das informações, dos conhecimentos e das obras." (LÉVY, 1999: 218)

\section{O fenômeno da remediação}

Os autores Jay Bolter e David Grusin cunham o termo remediação, definida como a representação de um meio de comunicação em outro meio, para assinalar um fenômeno importante para a compreensão dos 
fluxos de comunicação, em virtude da caracterização dos novos meios digitais (BOLTER \& GRUSIN, 2002: 45, tradução da autora).

Apresentar o conceito de remediação implica em rever também o conceito de meio de comunicação, definido pelos autores como aquilo que remedia ou é remediado, que se apropria das técnicas, formas e significado social de outro meio e busca competir com ele ou amoldá-lo: "Meio é aquele que remedia. É aquele que apropria das técnicas, formas e significado social de outros meios e busca rivalizá-los e remodelá-los em nome do real. Um meio em nossa cultura nunca pode operar isoladamente porque deve operar em relacionamentos de respeito e competição com outros" (BOLTER \& GRUSIN, 2000: 65, tradução da autora).

O conceito é empregado pelos autores para explicar não apenas o empréstimo de conteúdo de um meio de comunicação a outro, mas a um tipo mais complexo de transferência no qual um meio é incorporado, representado e aperfeiçoado por outro. As mídias digitais, como a Internet, sofreriam um constante processo de influências dialéticas com as outras mídias:

"Meios digitais não podem nunca alcançar este estado de transcendência - uma ruptura radical com o passado, mas, ao contrário, irão operar em uma constante dialética com meios mais antigos, precisamente como estes funcionaram quando surgiram" (BOLTER \& GRUSIN, 2002: 50, tradução da autora).

Os autores destacam sua importância para o mercado da comunicação e apontam sua passagem por diversos estágios, remediando e sofrendo remediação de outros meios, devido à sua imensa potencialidade para agregar formatos multimídia:

“A rede mundial de computadores já passou por inúmeros estágios, cada um deles remodelando alguma mídia anterior. A rede hoje é eclética e inclusive e continua a emprestar e remediar qualquer meio visual ou verbal" (BOLTER \& GRUSIN, 2002: 42, tradução da autora).

Antes do aparecimento do navegador Netscape, a Internet remediava apenas informações textuais. Como o surgimento do navegador, imagens estáticas puderam ser exibidas na rede, e como conseqüência, mais pessoas passaram a acessar a Internet, que se torna capaz de remediar não apenas informações textuais, mas também imagéticas. Conforme o número de usuários cresce e se intensifica o uso de ferramentas interativas, a Internet passa cada vez mais a ser um elemento remediador dos diversos tipos de meios de comunicação.

O início da prática jornalística na Internet se dá principalmente por meio da simples transposição do conteúdo impresso ao meio on-line. Ao longo dos anos, o uso das ferramentas interativas em jornais on-line, bem como as adaptações sofridas pelos textos em função dos novos recursos interativos lideram o jornalismo on-line a uma etapa hipermediática. O desenvolvimento dos veículos jornalísticos on-line nacionais está classificado em três etapas, de acordo com a categorização proposta por Machado e Palácios:

“Como resultado desta estratégia, para nossos propósitos, webjornalismo de primeira geração consiste na transposição de conteúdos dos demais meios, sem sistemas próprios de apuração; webjornalismo de segunda geração, que produz conteúdos próprios, mas sem sistemas de apuração, produção e circulação de conteúdos adaptados às redes 
digitais e webjornalismo de terceira geração, quando todas as etapas do trabalho jornalístico são desenvolvidas no ciberespaço, com adoção de sistemas descentralizados de produção" (MACHADO, 2003: 01).

Também denominada fase hipermediática, o jornalismo on-line de terceira geração, é caracterizado pela publicação e reedição dos conteúdos para diferentes formatos e linguagens, bem como pela redefinição de projetos gráficos e utilização de recursos multimídia. Esta evolução do jornalismo on-line é um reflexo das remediações sofridas e promovidas desde o nascimento da Internet como um meio de comunicação descentralizado, capaz de promover transformações estruturais em diversas instituições sociais.

A bilateralidade e a interatividade marcam a Internet como um meio no qual os papéis de emissor e receptor se confundem. A narrativa hipertextual não está na mão do emissor e sim do receptor, que escolhe como e quando acessar qualquer tipo de informação dentro da rede. Se no meio impresso, o jornalista tinha seus leitores na mão e guiava suas leituras, no meio on-line o leitor pode, a qualquer momento, deixar de ler o texto e acessar outro hiperlink. Quanto mais interativo for o jornalismo ali praticado, quanto mais voz ele der aos seus leitores, maior será o grau de aperfeiçoamento destes jornais, mais eles irão se diferenciar das mídias tradicionais.

Os diários virtuais podem ser interpretados como uma remediação do romance, da carta, do diário íntimo, do jornal diário, da televisão, da Internet e do jornal impresso. No entanto, como remediação não implica apenas em adaptação, transposição, mas também em complexificação os diários virtuais possuem diferentes características e funcionalidades daquelas do diário tradicional. A mudança do formato, neste caso, gera um novo meio de expressão no meio on-line, que faz parte do jogo da remediação. O uso da interatividade e a ausência de privacidade fazem dos diários digitais um meio de expressão com diferentes funções daquelas exercidas pelo diário tradicional. Popularizado no meio on-line, deixou de ser algo privado para se tornar público. Um meio híbrido, em função da remediação, com características da fotografia, do cinema, da televisão e dos diários íntimos.

A interatividade nos diários virtuais se dá, principalmente, pela ferramenta que permite aos leitores comentar os registros publicados pelo autor:

"Os diários virtuais incitam a participação de outra maneira - eles produzem blogueiros. Ler os pensamentos de outras pessoas, pessoas comuns de repente compreendem que na rede qualquer um pode ter voz, e leitores se tornam autores”.(BLOOD, 2002: 18, tradução da autora).

Hoje em dia, o diário virtual jornalístico remedia e é remediado pelo conteúdo noticioso dos portais. Parte do conteúdo publicado em diários virtuais de jornalistas é proveniente de sites agências de notícias e portais. Por outro lado, muitos jornais sofrem influência das características dos diários virtuais jornalísticos, que se tornam uma rica fonte de pautas para os jornalistas. Os diários virtuais sofrem remediação por parte da televisão, do rádio e dos jornais impressos e até da publicidade. 
Para Rebecca Blood, os diários virtuais, como formato genuíno da Internet, representam o primeiro passo em direção à sua originalidade: "O diário virtual pode ter diversas funções, mas é, acima de tudo, um formato genuíno da rede. A página inicial tradicional pode ser tanto um currículo ou um elaborado álbum de família, mas é geralmente uma tentativa de transferência de um produto em papel ao novo" (BLOOD, 2002: 09, tradução da autora).

Embora a autora não mencione a palavra "remediação", a transferência e adaptação de conteúdo de um meio de comunicação a outro estão claramente delineadas. Transposto o conteúdo das mídias tradicionais à rede, o texto é editado e transposto em hiperlinks, seu formato, fonte e tamanho se modificam, bem como a interface gráfica. No entanto, o conteúdo não ainda não havia sofrido grandes transformações, apesar das etapas pelas quais o jornalismo on-line passou. A remediação do conteúdo jornalístico só atinge sua potencialidade ótima com o surgimento dos diários virtuais, que favorece a troca de informações de modo bilateral e interativo.

\section{O Universal sem Totalidade}

Segundo Pierre Lévy, na tradição oral, as mensagens eram transmitidas em um mesmo contexto físico e temporal, não exigindo esforço de interpretação por parte do receptor para compreendê-la. No caso da cultura da escrita, as mensagens devem manter seu sentido, e, para isso, é necessário um esforço de interpretação para compreender a mensagem fora de seu contexto original de produção, fechamento semântico que caracteriza a universalidade da escrita.

Tanto a cibercultura quanto a escrita são universais, segundo o conceito de Lévy. O universal da escrita admite a totalidade de sentido, devido à falta de um contexto único. Uma mensagem escrita deve ser compreendida no mundo todo, não importa a data nem o local de origem. Há sempre um sentido que se fecha e este fechamento semântico é justamente exigido pela descontextualização espacial e temporal. No entanto, o universal da cibercultura não se articula sobre o fechamento semântico da descontextualização, ele não se totaliza, pois a interconexão geral entre os usuários não permite o fechamento semântico.

Para o autor, as mídias de massa tradicionais dão continuidade ao universal totalizante característico da escrita. As mensagens transmitidas por estes meios de comunicação visam os receptores no mínimo de sua capacidade interpretativa e interativa. No entanto, a capacidade de interconexão transforma o movimento da cibercultura em um universal sem totalidade de sentido, já que este pode ser reinterpretado a cada toque do mouse. "Essa universalidade desprovida de significado central, esse sistema da desordem, essa transparência labiríntica, chamo-a de "universal sem totalidade". Constitui a essência paradoxal da cibercultura." (LÉVY, 1999: 111)

A cibercultura dissolve a pragmática da reunião entre a universalidade e a totalidade que predominava desde a invenção da escrita. Ela "nos leva, de fato, à situação existente antes da escrita - mas em outra escala e em outra órbita - na medida em que a interconexão e o dinamismo em tempo real das memórias on-line tornam novamente 
possível, para os parceiros da comunicação, compartilhar o mesmo contexto, o mesmo imenso hipertexto vivo.” (LÉVY, 1999: 118)

O jornal impresso, como típico dispositivo comunicacional unidirecional, presume a totalidade de sentido isto é, o fechamento semântico. No entanto, sua simples reprodução para a plataforma digital, caracterizada pela bidirecionalidade constitui uma um sub-aproveitamento do recurso da interconexão generalizada, oferecido pela cibercultura, na qual cada usuário constrói o sentido que deseja para a mensagem que lê. Para Lévy, o ciberespaço encoraja uma troca recíproca e comunitária, enquanto as mídias clássicas praticam uma comunicação unidirecional na qual os receptores estão isolados uns dos outros: "Existe, portanto, uma espécie de antinomia, ou de oposição de princípios, entre as mídias e a cibercultura, o que explica o reflexo deformado que uma oferece da outra para o público".(LÉVY, 2003: 203).

Por serem meios de comunicação unidirecionais, as mídias de massa não fornecem a liberdade necessária para que as mensagens transmitidas fujam do contexto original pregado. Apenas a cibercultura possibilita esta abertura de sentido, uma vez que seus participantes são ativos na produção do sentido das mensagens transmitidas e devido ao ciberespaço caminhar em direção à integração, à interconexão, ao estabelecimento de sistemas cada vez mais interdependentes, universais e transparentes.

A partir do momento em que o jornal impresso é remediado pelo ciberespaço, as notícias apenas adquirem novo formato, passam de um dispositivo comunicacional unidirecional para um bidirecional. Apesar do desenvolvimento do jornalismo on-line ao longo dos últimos dez anos, as notícias ainda seguem o modelo de comunicação unidirecional, o jornalismo brasileiro praticado na rede ainda se propõe como unilateral, proveniente de um grupo seleto de empresas informativas, embora se busque o máximo aproveitamento dos recursos on-line e apesar dos leitores terem acesso ao grande banco de dados noticiosos na Internet. No entanto, esta perspectiva deve se modificar ao longo dos anos, conforme o jornalismo on-line for encontrando seu nicho, fenômeno no qual o diário virtual exerce total influência.

Assim, a mera transposição dos conteúdos de outras mídias para sua aglutinação em rede não satisfaz audiências que tem um poder de interação com os emissores da mensagem muito maior que em outros veículos de comunicação. Uma ferramenta que favorece a interconexão, como o diário virtual, é área fértil para o florescimento de manifestações criativas individuais que expressam visões alternativas de mundo. Ele surge como um escapismo à totalidade semântica das mídias de massa reproduzidas no ciberespaço, remediação alternativa aos/destes meios, uma vez que os jornalistas podem escrever o que quiserem apoiados ou não no que está sendo veiculado pelo jornal impresso e favorecem a emergência de uma maior multiplicidade de sentidos em comparação ao jornalismo tradicional. Frente à encruzilhada do jornalismo adaptado e remediado pela Internet, mas ainda ligado essencialmente preso aos estilos e práticas do jornalismo impresso, os diários virtuais jornalísticos apontam como uma nova perspectiva de vazão criativa aos jornalistas. 


\section{A metamorfose da atividade jornalística promovida pelo diário virtual}

A remediação sofrida e promovida pela Internet propõe novos caminhos à divulgação noticiosa no mercado de comunicação nacional. Deslocada de uma máquina de produção da notícia em série, composta por profissionais especializados movidos em torno de uma coletividade corporativista para a expressão informativa individualista na rede, a atividade jornalística toma contornos diferenciados por meio dos diários virtuais.

O ciberespaço amplia as noções de espaço e tempo e implode os limites que norteiam a produção do texto jornalístico. O espaço físico do jornal delimitado por sua materialidade do papel e a periodicidade imposta pelo ritmo diário de publicação, elementos essenciais ao jornalismo, perdem seus referenciais no meio virtual. O desenvolvimento tecnológico subverte as antigas noções de jornalismo como uma atividade especializada e do jornalista como um mediador entre a imprensa e o público.

A mensagem jornalística tradicional, de certo modo, está perdendo seu poder de promotora e criadora da informação e de formadora de opinião, deixa de ser única fonte de verdade do mundo contemporâneo, face às diversas outras possibilidades abertas pelo mundo do ciberespaço:

"Se cada pessoa pode emitir mensagens para várias outras, participar de fóruns de debates entre especialistas e filtrar o dilúvio informacional de acordo com seus próprios critérios (o que começa a tornar-se tecnicamente possível), seria ainda necessário, para se manter atualizado, recorrer a esses especialistas da redução ao menor denominador comum que são os jornalistas clássicos?”. (LÉVY, 1999: 188)

Um dos principais elementos da mídia tradicional que não se mantiveram nos diários virtuais é a figura do gatekeeper, aquele, dentro do quadro de funcionários de um jornal, determina quais notícias serão lidas pelos leitores no dia seguinte á reunião de pauta. Durante anos, o gatekeeper tem sido uma das figuras mais poderosas dos meios de comunicação, delineando tendências e controlando o fluxo de informação.

No jornalismo on-line, o gatekeeper ainda está presente, pois ainda é necessário continuar a selecionar informação a partir daquilo que se pensa que são os interesses dos consumidores. Embora parte do conteúdo publicado nos grandes portais seja proveniente dos diários virtuais produzidos por jornalistas, o processo de pauta e seleção da notícia, bem como de escolha de fontes, apuração e edição não são dispensados, uma vez que asseguram a tradicional impressão de imparcialidade e a conseqüente credibilidade.

A etapa de filtragem de informações e captações e a figura do gatekeeper, especializado na função, inexistem no diário virtual, pois estas tarefas são exercidas diretamente pelo seu autor, que capta a informações, escreve e edita e as publica.

$\mathrm{Na}$ Internet, tudo pode fornecer informação, desde sites jornalísticos até institucionais e pessoais. Os diários virtuais jornalísticos são uma alternativa aos interesses de empresas de mídias de massa em determinar as notícias que serão veiculadas no ciberespaço: “como já enfatizei diversas vezes, o ciberespaço é justamente uma alternativa para as mídias de massa clássicas. De fato, permite que os indivíduos e os grupos encontrem as informações 
que lhes interessam e também que difundam sua versão dos fatos (inclusive com imagens) sem passar pela intermediação dos jornalistas" (LÉVY, 1999: 203).

A inserção do diário virtual jornalístico deu uma nova dimensão à interatividade no jornalismo online. Ao invés de se comunicar com o veículo, o leitor pode se comunicar diretamente com o jornalista. A reciprocidade aqui é acentuada. E se o autor do diário utilizar vídeos e imagens, a interatividade se mostra ainda mais eficiente. Em seu diário virtual, o jornalista pode estimular a fruição criativa de textos e aproveitar o testemunho ocular para se tornar personagem em sua própria matéria, numa espécie de jornalismo literário, gênero que permite a escrita em primeira pessoa, de acordo com a visão pessoal do autor.

O diário virtual é uma das maneiras para diferenciar-se da reprodução não criativa da mídia impressa e aproveitar o máximo que a interconexão geral possibilita aos internautas e uma forma de impedir a dominação do fluxo de informação que controla a opinião pública, bem como a homogeneização das pautas e notícias no mercado informativo nacional.

\section{Entre a utopia e o ceticismo}

Argumentada a enorme potencialidade dos diários virtuais jornalísticos como meio alternativo às mídias de massa, a discussão a respeito dos diários virtuais toma contornos radicais quando chamada a responder pela profecia utópica da democratização da informação que seria promovida pela Internet. Os diários virtuais jornalísticos se tornam, assim, alvos principais da concretização do jornalismo cidadão, como é denominado pelos pesquisadores Bowman e Willis, o ato dos cidadãos terem um papel ativo no processo de coleta, reportagem, análise e distribuição de notícias e informações, com a intenção de fornecer informação independente, confiável, precisa, abrangente e relevante.

Posições extremistas frente às inovações tecnológicas atingem a discussão a respeito das funções dos diários virtuais. Sua condição jornalística tem sido debatida incessantemente por jornalistas e teóricos norteamericanos desde a popularidade que os diários virtuais tomaram após os ataques terroristas em setembro de 2001. Para utópicos, a liberdade de expressão favorecida pelo diário virtual seria capaz de transformar qualquer cidadão em jornalista, subvertendo a hierarquia de poder perpetuada pelos grandes conglomerados midiáticos. Para os céticos, uma ferramenta inexpressiva e incapaz de modificar as estruturas empresariais e financeiras a tal ponto de fazer desaparecer a figura do jornalista.

Entretanto, a condição jornalística dos diários virtuais é definida ora de acordo com o modo de produção da notícia, ora de acordo com o conteúdo que divulga (segundo os quatro elementos essenciais ao conteúdo jornalístico: atualidade, periodicidade, universalidade e publicidade), ora dependendo do autor do diário virtual (muitos diários virtuais são denominados jornalísticos simplesmente por serem escritos por jornalistas, independente do conteúdo divulgado ou do modo de produção deste conteúdo). Outro dado que 
torna ainda mais complexa a condição jornalística dos diários virtuais é o fato de que, da mesma maneira que pessoas comuns podem construir produtos jornalísticos em diários virtuais de acordo com as características da periodicidade, da aparição pública, da diversidade de conteúdo, do interesse geral, da atualidade e do profissionalismo, jornalistas são contratados por grandes conglomerados jornalísticos para publicar conteúdo em diários virtuais próprios.

\section{O conceito de jornalismo cidadão}

Entre os entusiastas do diário virtual como ferramenta que revoluciona as estruturas de poder das grandes empresas informativas, populariza-se o jornalismo cidadão ou participativo, defendido como um novo tipo de jornalismo, que teria como produtores e divulgadores da informação as pessoas comuns, as quais poderiam ser chamadas de jornalistas.

O jornalista e guru do jornalismo cidadão Dan Gillmor, profetiza a transformação do jornalismo, de um meio de comunicação de massas do século XX até algo mais profundamente cívico e democrático, pois: "a tecnologia dotou-nos de um conjunto de ferramentas de comunicação capaz de nos transformar a todos em jornalistas, com custos reduzidos e, em teoria, com acesso a um público global” (GILLMOR, 2005: 14).

A democratização do acesso à informação possibilita que qualquer pessoa seja uma interlocutora dos acontecimentos que ocorrem à sua volta. Neste sentido, os diários virtuais fazem parte das ferramentas inovadoras que permitiriam, segundo alguns militantes, a produção e a veiculação de notícias desvinculadas do processo de criação tradicional da notícia. O jornalista Hugh Hewitt defende que os diários virtuais ganham dos grandes conglomerados de mídia na corrida pela busca e pela distribuição da informação. Os vários estágios de produção e disseminação da notícia em jornais, revistas, rádio e televisão alongam o tempo entre a captação do fato pelo repórter e a sua distribuição. No diário virtual, não há este intervalo, pois seu conteúdo é captado, escrito e divulgado pela mesma pessoa.

Para os adeptos e ativistas desta prática, o jornalismo cidadão surge como uma chance de democratizar a informação, a partir do momento em que qualquer pessoa teria acesso à mídia, não apenas como leitor ou espectador, mas colaborando na produção do material veiculado. Os diários virtuais de conteúdo jornalístico seriam poderosos meios de distribuição de informação devido às suas características descentralizadas. Seu conteúdo é distribuído pela rede e as perspectivas são variadas, permitindo aos leitores ter acesso a variados pontos de vista sobre o mesmo assunto. Estas características são benéficas, uma vez que não existe censura e não ocorrem problemas com relação a excesso de tráfego, transformando os diários virtuais em ferramentas de utilidade pública em caso de catástrofes e emergências.

O jornalismo cidadão se apóia no conceito de notícia como o relato ou registro de um fato importante para uma pessoa ou um grupo e com algum elemento de novidade. Para fazer notícia, seria preciso contar com 
informações confiáveis, presenciando um fato, entrevistando quem presenciou ou reunindo informações a partir de boas fontes. Assim, o jornalismo cidadão não deixaria de lado as regras de apuração jornalísticas. No entanto, o que se verifica, na prática, no país, é a simples reprodução de notícias provenientes de grandes jornais em diários virtuais, ou mesmo alguns relatos que não podem ser caracterizados como jornalísticos, uma vez que não seguem tais regras.

O colunista norte-americano John Dvorak é conhecido como um dos maiores opositores ao jornalismo cidadão, e crítico das iniciativas de entusiastas como Dan Gillmor e Jeff Jarvis, chamados por ele de idealistas: "Um jornalista-cidadão não é nada mais do que alguém que adiciona comentários a fóruns de discussão - o que é risível. Para reflexão, eu sugeriria uma lista de blogueiros locais - e anotaria que a maioria deles se auto-denominam blogueiros, e não jornalistas."(tradução da autora) ${ }^{3}$

Para Jose Luis Orihuela, professor da Universidade de Navarra, autor do livro La Revolución de los Blogs, o conceito de jornalismo-cidadão é inadequado para compreender a revolução que está ocorrendo. Jornalismo seria algo que se estuda, que aparece em alguns meios, segundo regras de ética e deontologia e de função social muito importante. O que se chama de jornalismo cidadão são meios sociais, não somente em diários virtuais, mas também em todas as tecnologias de informação que permitem que pessoas comuns possam fazer comunicação pública, até de boa qualidade como a Wikipedia, "mas não o chamaria de jornalismo cidadão, por que não existe jornalismo sem jornalistas. Há algumas pessoas fazendo coisas respeitáveis em geral e valiosas, mas que não são jornalismo e é uma falta de respeito que o chamem assim". 4

Blood argumenta que autores de diários virtuais não se transformam em jornalistas simplesmente porque escrevem a respeito destes acontecimentos. Supor que a mídia tradicional desaparecerá em virtude da popularização dos diários virtuais de conteúdo jornalístico seria um contra-senso, pois os diários virtuais não seriam um novo tipo de jornalismo:

“Os diários virtuais não são, como dizem alguns, um novo tipo de jornalismo. Mais propriamente, eles suplementam o jornalismo tradicional com avaliações, comentários e, acima de tudo, filtragem da informação produzida mecanicamente pela imprensa." (BLOOD, 2002: 23, tradução da autora).

Assim, o surgimento de diários virtuais com funções jornalísticas tem gerado muitas discussões entre comunicadores. A primeira questão colocada debate se este serviço prestado pelos cidadãos pode ser mesmo considerado jornalismo, compreendido não apenas pela pressuposição de um conteúdo noticioso, mas também por seu modo de produção e pela sua prática. E esta questão esbarra na polêmica suscitada por Orihuela e Blood, na determinação de que apenas profissionais da informação poderiam produzir conteúdo jornalístico. Aqui, o caráter jornalístico da notícia está diretamente ligado àqueles que a produzem e a condição jornalística dependeria de um modo de produção profissional, que pressupõe a atividade jornalística não apenas em função de seu conteúdo, mas também em função do emprego da fonte, da edição e da imparcialidade. 
O processo de fabricação da notícia inclui entrevistar testemunhas e especialistas, checar fatos, comparar dados, escrever, editar e disseminar a notícia. Cada etapa é desenvolvida com a finalidade de produzir um material consistente que será publicado pela agência noticiosa. O processo de produção no diário virtual não passa por estas etapas. Seus conteúdos não são direcionados por editores, nem checados e comparados e não devem responder a ninguém. Embora o conceito de jornalismo cidadão proponha o uso de regras de apuração, checagem e a imparcialidade, muitas vezes, são ignoradas pelos que se autodenominam jornalistas-cidadão, que acabam deixando de lado os passos para a construção da notícia.

O jornalismo-cidadão é alvo de críticas não apenas de estudioso da mídia, mas também de jornalistas e órgãos comunicacionais. Tal é o caso do jornal The New York Times que considera que o jornalismo cidadão abandonou o grande princípio do jornalismo: a objetividade.

O chamado jornalista-cidadão conta a sua versão dos fatos, de modo subjetivo, sem se ater aos princípios de objetividade pelos quais clamam os jornalistas. Não se compromete com a imparcialidade tida como necessária à ética jornalística. Para os profissionais do jornalismo, o jornalismo cidadão não é mais do que a mera opinião de alguém relativamente a um determinado assunto, pelo que este novo jornalismo é visto como um jornalismo opinativo e parcial.

Assim, uma outra questão central coloca constantemente é sobre a ética das notícias produzidas por cidadãos. Vários jornalistas questionam como é que notícias produzidas sem regras e sem técnicas jornalísticas podem seguir uma ética profissional? Se o jornalismo cidadão não segue regras jornalísticas como podem os leitores ter a certeza que os fatos relatados são verdadeiros? Esta é, pois, a grande falha do jornalismo cidadão. Neste "novo jornalismo" ninguém garante a veracidade dos fatos, aos leitores não é apresentado um índice de credibilidade pautado pelo prestígio da empresa informativa reconhecida.

No entanto, como se explica a popularidade que estes diários virtuais passaram a ter? A resposta, longe de ser conclusiva, aponta para um caminho no qual a subjetividade na qual se apóiam os diários virtuais entra em concordância com a interconexão generalizada e a conseqüente ausência de fechamento semântico no meio on-line, em um aproveitamento dos recursos interativos que favorecem a narração individual de um fato. A objetividade e imparcialidade nas quais o jornalismo encontra suas bases são minadas e se descortina a aparente objetividade que se presumia existir entre o jornalista que quer traduzir o mundo e o fato a ser noticiado.

Segundo estudo publicado no jornal The Guardian, em julho de 2006, de cada cem usuários, apenas um quer produzir algo, 10 irão interagir com este conteúdo, comentando-o e outros 89 irão apenas visualizá-lo (tradução da autora). ${ }^{5}$ Esses dados provam a importância da audiência na Internet e ilustram a dinâmica da produção noticiosa em diários virtuais: poucos são os que realmente se propõem a desenvolver mecanismos jornalísticos de criação da notícia. A popularidade destes diários é mais proveniente da repercussão de pequena 
porcentagem de diários virtuais entre os muitos leitores e menos da produção de uma grande quantidade de informação noticiosa.

\section{Em busca de conclusões}

Longe de ignorar a intensidade e a importância da revolução que estes novos formatos são capazes de produzir, deve-se separar o jornalismo praticado em órgãos informativos daquela atividade expressiva de indivíduos interessados na produção de informação. Diários virtuais são um componente vital de uma mídia saudável, no entanto, ainda estão longe de poderem ser considerados como jornalismo. A função dos diários virtuais é impossível de ser reproduzida pelo jornalismo tradicional e o que o jornalismo faz é impraticável para um diário virtual.

Surgem como uma forma de complementar algumas lacunas no jornalismo praticado na Internet e atua como fonte de pautas aos jornais e como elemento introdutor de uma nova narrativa, pessoal e próxima do jornalismo literário, além de emprestar conteúdos destes jornais, disponibilizado-os por meio dos hiperlinks.

Assim, rejeita-se a idéia de que os diários virtuais suplantariam as mídias tradicionais e redefinem-se suas funções: o segundo, marcado pela supremacia da audiência e o primeiro, à margem do segundo. Estar à margem, no entanto, não implica uma relação de parasitismo, e sim de complexificação e aperfeiçoamento. Ambos se beneficiariam se desistissem de definir diários virtuais como jornalismo ou de expandir a definição de jornalismo para incluir este novo formato. Preferivelmente, cada um deveria reconhecer os valores do outro e ambos mover-se na direção de seus aperfeiçoamentos. 


\section{Referências bibliográficas}

BOLTER, Jay David; GRUSIN, Richard. Remediation: understanding New Media. Cambridge: The MIT Press: 2002.

BLOOD, Rebecca, The Weblog Handbook: Practical Advice on Creating and Maintaining Your Blog, Perseus Publishing: 2002.

GILLMOR, Dan. Nós, Os Media. Editorial Presença: 2005.

HEWITT, Hugh. Blog: Understanding the Information Reformation That's Changing Your World. Nokomis,

FL: Nelson Business: 2005.

LÉVY, Pierre. Cibercultura. São Paulo, Ed. 34: 1999.

MACHADO, Elias e PALACIOS, Marcos. Modelos de Jornalismo Digital. Salvador, Calandra: 2003.

ORIHUELA, José Luis, La revolución de los blogs, La Esfera de los libros, Madrid: 2006

\section{Artigos e entrevistas pesquisadas}

http://www.cordoba.net/notas.asp?idcanal=36\&id=46082 acessado em 10/06/2007

http://www.pcmag.com/article2/0,1895,2019483,00.asp acessado em 10/06/2007

http://technology.guardian.co.uk/weekly/story/0,1823959,00.html acessado em 10/06/2007

\footnotetext{
${ }^{1}$ Trabalho apresentado no Encontro dos Núcleos de Pesquisa em Comunicação - NP Tecnologias da Informação e da Comunicação, no XXX Congresso da Sociedade Brasileira de Estudos Interdisciplinares em Comunicação (Intercom), realizado de 29/08 a 02/09/2007 na Universidade Católica de Santos (SP). O texto foi escrito a partir de pesquisa de Iniciação Científica intitulada "Novas perspectivas do jornalismo brasileiro na internet: os diários virtuais de conteúdo jornalístico", realizada no ano de 2006 com apoio da Fapesp.

${ }^{2}$ Mestranda no Programa de Pós-Graduação em Ciências da Comunicação da Escola de Comunicações e Artes da Universidade de São Paulo (ECA-USP), sob orientação da profa. dra. Rosana de Lima Soares. É bolsista Fapesp, desenvolvendo a pesquisa "Diários de vitrine: caminhos comunicativos no contexto discursivo do meio digital".

${ }^{3} \mathrm{Em}$ http://www.pcmag.com/article2/0,1895,2019483,00.asp acessado em 10/06/2007

${ }^{4} \mathrm{Em}$ http://www.cordoba.net/notas.asp?idcanal=36\&id=46082 acessado em 10/06/2007

${ }^{5} \mathrm{Em}$ http://technology.guardian.co.uk/weekly/story/0,,1823959,00.html acessado em 10/06/2007
} 